\title{
Biomonitoring of air pollution in Slovenia and Germany: Did the COVID-19 lockdown reduce trace metal contents of Sphagnum mosses?
}

\author{
ELKE BOZAU ${ }^{1}$ AND NINA ZUPANČIČ ${ }^{2}$
}

${ }^{1}$ TU Clausthal

${ }^{2}$ University of Ljubljana

Presenting Author: ebozau@gmx.de

Sphagnum mosses are useful bioindicators for air pollution (e.g., Wojtun et al., 2013). Since 2017, moss samples have been collected in Slovenian and German bogs. The samples were carefully washed in deionized water, ground, digested with aqua regia and analyzed for main components, REE and trace elements by ICP-MS with the aim to compare atmospheric deposition in similar ecosystems of both countries. Due to the lockdown to stop COVID-19 infections, air pollution (e.g., $\mathrm{NO}_{2}$, $\mathrm{CO}$ and particulate matter) especially in industrial areas was reduced in 2020 (Chen et al., 2020; Lian et al., 2020). The reduction of anthropogenic particulate matter should be seen in Sphagnum mosses, too. Russian moss data (Yushin et al., 2020) did not reflect this reduction. Our data of Slovenian and German mosses also show no significant reduction for the majority of investigated trace metals after the Corona lockdown in spring 2020. But a different elemental behaviour is found at several sampling points. Lower $\mathrm{Pb}$ contents of Sphagnum mosses were found in mosses of several geological units in the Harz Mountains (Germany) and in Pokljuka (Slovenia) in 2020, whereas constant contents are seen around Moscow (Russia) and Pohorje (Slovenia) in 2019 and 2020. Slovenian moss samples show in general lower contents of trace elements than the German moss samples.

Chen, L.-W. A., Chien, L.-C., Li, Y., Lin, G., 2020. Nonuniform impacts of COVID-19 lockdown on air quality over the United States. Sci. Tot. Environ. 745, 141105.

Lian, X., Huang, J., Huang, R., Liu, C., Wang, L., Zhang, T., 2020. Impact of city lockdown on the air quality of COVID-19hit of Wuhan city. Sci. Tot. Environ. 742, 140556.

Wojtun, B., Samecka-Cymerman, A., Kolon, K., Kempers, A.J., 2013. Decreasing concentrations of metals in Sphagnum mosses in ombrotrophic mires of the Sudety mountains (SW Poland) since late 1980s. Chemosphere 91, 1456-1461.

Yushin, N., Chaligava, O., Zinicovscaia, I., Vergel, K., Grozdov, D., 2020. Mosses as bioindicators of heavy metal air pollution in the lockdown period adopted to cope with the COVID-19 pandemic. Atmosphere 11, 1194. 